\title{
Use of a Modified Ultrafiltration Technique during Aortic Valve Replacement Surgery on a Jehovah's Witness
}

\author{
Hobum Cho \\ Department of Anesthesiology and Pain Medicine, Soonchunhyang University Seoul Hospital, Seoul, Korea
}

\begin{abstract}
Jehovah's Witnesses do not accept blood transfusions, rendering open-heart surgery difficult. A 77-year-old female was scheduled for elective bloodless surgery to replace an aortic valve. When cardiopulmonary bypass concluded, all ultrafiltrated blood was re-infused using a modified ultrafiltration technique. We encountered no intraoperative or postoperative complications. Anesthesiologists should consider modified ultrafiltration when a patient refuses a blood transfusion.
\end{abstract}

Keywords: Bloodless medical and surgical procedures; Cardiopulmonary bypass; Ultrafiltration

\section{INTRODUCTION}

Jehovah's Witnesses do not permit the transfusion of allogeneic blood or blood products. Generally, they accept most medical treatments, surgical procedures, and fluids such as crystalloids, colloids, and starch [1]. Proposed treatments should be carefully discussed with the patient and family to clarify exactly what is acceptable.

Open heart surgery is commonly associated with massive bleeding requiring extensive blood transfusion. It is not easy to avoid transfusion. However, new blood conservation techniques allow cardiac surgery to be safely performed without transfusion [2]. Modified ultrafiltration (MUF) is a valuable blood conservation strategy after cardiopulmonary bypass (CPB). We present a case (a Jehovah's Witness) who underwent bloodless aortic valve replacement surgery using MUF.

\section{CASE REPORT}

A 77-year-old female (weight, $43 \mathrm{~kg}$; height, $149 \mathrm{~cm}$ ) of American Society of Anesthesiologists physical status 3 was admitted because of epigastric pain. She has been taking of calcium channel blocker and angiotensin II receptor blocker for the blood pressure and has no other past history. She had been diagnosed (in another hospital) with rheumatic aortic regurgitation and was transferred to us for elective bloodless aortic valve replacement surgery. After the surgery was decided, intravenous ferric carboxymaltose 500 mg was administered to improve the hemoglobin level.

Upon arrival in the operating theater without premedication, standard monitoring devices, including a five-lead electrocardiogram machine; a pulse oximeter; and an oscillometric, noninvasive blood pressure cuff were applied. Before the induction of anesthesia, an arterial cannula was inserted into the right radial artery to allow continuous arterial blood pressure monitoring and blood sampling after confirming that the modified Allen test was positive. After the infusion of intravenous lidocaine $(0.5 \mathrm{mg} / \mathrm{kg})$, general anesthesia was induced and maintained with total intravenous anesthesia. Propofol and remifentanil were delivered with effect-site targeting using a target-controlled infusion system (Orchestra Primea; Fresenius Kabi AG, Bad Homburg, Germany). Propofol levels were monitored using the Schnider pharmacokinetic model and remifentanil levels monitored employing the Minto model. The target concentrations of propofol and remifentanil were $3 \mu \mathrm{g} / \mathrm{mL}$ and $2 \mathrm{ng} / \mathrm{mL}$ during induction and were maintained at $2 \mu \mathrm{g} / \mathrm{mL}$ and $1-3 \mathrm{ng} / \mathrm{mL}$, respectively, despite any hemodynamic change. After the loss of the eyelash reflex, a bolus dose 
of rocuronium $(0.6 \mathrm{mg} / \mathrm{kg})$ was administered; tracheal intubation was performed using a 7.0-mm endotracheal tube (Shiley; Covidien, Mansfield, MA, USA) and a McGrath videoscope (Aircraft Medical Ltd., Edinburgh, UK). The insertion depth was $22 \mathrm{~cm}$ from the upper incisors. Subsequently, we inserted a multi-lumen access catheter (a two-lumen central venous access device; Arrow International, Reading, PA, USA) into the right internal jugular vein under ultrasonographic guidance using the Seldinger technique. This proceeded under sterile conditions with the patient in the Trendelenburg position.

Preoperatively, the hemoglobin/hematocrit $(\mathrm{Hb} / \mathrm{Hct})$ ratio was $14.2 / 44.1$, and the platelet number $219,000 / \mu \mathrm{L}$. We scheduled an intraoperative autologous blood transfusion (a 'donation') of $600 \mathrm{~mL}$ via acute normovolemic hemodilution $(\mathrm{ANH})$ after cannulation of the arterial line. However, soon after ANH commenced, the blood pressure fell and the hemodynamics became unstable; only $200 \mathrm{~mL}$ of blood was delivered.

The CPB pump was a Sorin Stockert C5 fitted to an S5 heart-lung machine with a centrifugal blood pump and a heater-cooler device (SorinStockert Instrumente GMBH, Munich, Germany); the circuit was primed with albumin and mannitol. MUF for heparinized patients is performed between the arterial and the venous tubes of the bypass circuit using a Minntech Hemocor HPH 1000 TS filter (Medivators Inc., Minneapolis, MN, USA) with an effective membrane area of $1.1 \mathrm{~m}^{2}$ and a molecular weight cut-off of $65 \mathrm{kDa}$. Intraoperative mediastinal blood shed before and after the bypass was salvaged with the aid of a cell separation device (Cell Saver System [Medtronic Autolog]; Medtronic Inc.).

The fluids administered during operation included $700 \mathrm{~mL}$ of crystalloid and $400 \mathrm{~mL}$ of colloid. All ultrafiltrated blood was reinfused at the end of CPB, as were $200 \mathrm{~mL}$ of salvaged blood and $200 \mathrm{~mL}$ of the autologous donation. During operation, the urine output was $200 \mathrm{~mL}$ and bleeding totaled $400 \mathrm{~mL}$. The total anesthesia time was 310 minutes and the operation time 240 minutes. The patient was transferred to the intensive care unit, under sedation, without any cardiovascular event.

The postoperative $\mathrm{Hb} / \mathrm{Hct}$ ratio was $10.1 / 32.5$ and the platelet number $97,000 / \mu \mathrm{L}$; there was no postoperative bleeding. The $\mathrm{Hb} /$ Hct ratio was $9.5 / 31.3$ and the platelet number $116,000 / \mu \mathrm{L}$ on a postoperative day (POD) 5. On POD 12, the vital signs were stable; the $\mathrm{Hb} / \mathrm{Hct}$ ratio was $10.2 / 32.8$, and the platelet number $188.000 / \mu \mathrm{L}$. The patient was discharged.

The patient provided written informed consent for publication of the research details.

\section{DISCUSSION}

Individual patient needs, values, and beliefs must be assessed, acknowledged, and respected. Especially, treatments acceptable to Jehovah's Witnesses must be clearly established and documented. The risks and benefits of any procedure, including any additional risk imposed by blood refusal, should be considered and discussed with the patient [3]. This is particularly important if surgery is associated with large blood volume shifts, as is the case during open heart surgery.

Re-infusion of residual blood from the extracorporeal circuit (ECC) is one of the most important blood conservation techniques used during modern open heart surgery [4]. The ECC contains a large amount of diluted autologous whole blood at the end of CPB. However, this blood is often discarded or only partially salvaged because it might trigger systemic inflammatory response syndrome or impair coagulation status because of the hemodilution $[5,6]$.

MUF has features filtering of blood after bypass, removing water and low-molecular-weight substances, and rendering it possible to re-infuse the blood. Most prior reports on MUF featured pediatric patients [7-9]. However, Luciani et al. [10] showed that MUF during adult cardiac operations was associated with reduced early morbidity and lower transfusion requirements. Our patient was elderly, but we encountered no complication. The Hb level, the Hct, and the platelet count gradually improved after surgery.

Conventional bloodless surgery features $\mathrm{ANH}$, autologous blood transfusion, and blood salvage. For cases undergoing open heart surgery with $\mathrm{CPB}, \mathrm{MUF}$ contributes greatly to autologous whole blood salvage [3]. There is a worldwide shortage of safe and viable allogenic donor blood [11]. MUF is useful during open heart surgery, reducing the need for blood transfusion and the associated complications.

In conclusion, MUF after CPB can reduce the need for blood transfusion. Anesthesiologists should consider MUF when a patient refuses a blood transfusion.

\section{ACKNOWLEDGMENTS}

This work was supported by the Soonchunhyang University Research Fund. 


\section{REFERENCES}

1. Sacks DA, Koppes RH. Blood transfusion and Jehovah's Witnesses: medi$\mathrm{cal}$ and legal issues in obstetrics and gynecology. Am J Obstet Gynecol 1986;154:483-6.

2. Ott DA, Cooley DA. Cardiovascular surgery in Jehovah's Witnesses: report of 542 operations without blood transfusion. JAMA 1977;238:1256-8.

3. Gohel MS, Bulbulia RA, Slim FJ, Poskitt KR, Whyman MR. How to approach major surgery where patients refuse blood transfusion (including Jehovah's Witnesses). Ann R Coll Surg Engl 2005;87:3-14.

4. Moskowitz DM, Klein JJ, Shander A, Cousineau KM, Goldweit RS, Bodian $\mathrm{C}$, et al. Predictors of transfusion requirements for cardiac surgical procedures at a blood conservation center. Ann Thorac Surg 2004;77: 626-34.

5. Kirklin JK, Blackstone EH, Kirklin JW. Cardiopulmonary bypass: studies on its damaging effects. Blood Purif 1987;5:168-78.
6. Westaby S. Organ dysfunction after cardiopulmonary bypass: a systemic inflammatory reaction initiated by the extracorporeal circuit. Intensive Care Med 1987;13:89-95.

7. Elliott MJ. Ultrafiltration and modified ultrafiltration in pediatric open heart operations. Ann Thorac Surg 1993;56:1518-22.

8. Kameyama T, Ando F, Okamoto F, Hanada M, Yamanaka K, Sasahashi N, et al. The effect of modified ultrafiltration in pediatric open heart surgery. Ann Thorac Cardiovasc Surg 2000;6:19-26.

9. Ootaki Y, Yamaguchi M, Oshima Y, Yoshimura N, Oka S. Effects of modified ultrafiltration on coagulation factors in pediatric cardiac surgery. Surg Today 2002;32:203-6.

10. Luciani GB, Menon T, Vecchi B, Auriemma S, Mazzucco A. Modified ultrafiltration reduces morbidity after adult cardiac operations: a prospective, randomized clinical trial. Circulation 2001;104:I253-9.

11. Napolitano LM. The most serious motivation for the development of a blood substitute is the worldwide shortage of safe and viable allogeneic donor blood: preface. Crit Care Clin 2009;25:xi-xii. 